\title{
Item Analysis of Measuring STEM Teachers' Practice in Higher-Order Thinking Skills Questioning Using Rasch Model
}

\author{
Nor'Aida Khairuddin ${ }^{1 *}$ and Rohaya Talib ${ }^{2}$ \\ ${ }^{1,2}$ School of Education, Faculty of Social Science and Humanities, Universiti Teknologi Malaysia, Malaysia
}

\begin{abstract}
.
For interdisciplinary approach in STEM integration, HOTS questioning application is part of inquiry-based learning which helps learners to construct knowledge by discovering new concepts and developing design thinking. In Malaysia, STEM teachers still insufficient to construct HOTS questions in teaching and learning session. This study aims to analyse HOTS questioning practice items using the Rasch model in terms of validity and reliability. The inventory was developed to measure STEM teachers HOTS questioning practice from five dimensions such as external world view, classroom interactions, deep and analytical thinking and complex thinking strategies using Likert type scale. The pilot study was conducted in eight secondary schools which involved 86 upper secondary STEM teachers. WINSTEPS version 3.72.3 was applied to analyse the pilot study outcomes. The results showed that the reliability based on Cronbach Alpha is 0.97 . The construct validity was determined by positive Point Measure Correlation (PMC) value, infit and outfit MSNQ between 0.4 to 1.5 and ZSTD range from -2.0 to 2.0. The summary statistics showed that person and item reliability were 0.97 and 0.95 , respectively. The person separation index with the value of 5.39 and item separation index, 4.59 were considered as excellent separation. Finally, for unidimensionality, raw variance explained by measure was $49.1 \%$, and the unexplained variance in the first factor was $6.7 \%$ meet the criteria Therefore, after eliminating the unfit items, the results demonstrated that this inventory was valid and reliable to measure STEM teachers HOTS questioning practice in future.
\end{abstract}

Keywords: STEM Integration, HOTS Questioning, Item Analysis, Rasch Model, Interdisciplinary STEM 